\title{
High seroprevalance of Neospora caninum in dogs in Victoria, Australia, compared to 20 years ago
}

\author{
Sarah Sloan ${ }^{1,2}$, Jan Šlapeta ${ }^{3}$, Abdul Jabbar ${ }^{4}$, Jaimie Hunnam5 ${ }^{5}$ Bert De Groef ${ }^{2}$, Grant Rawlin
} and Christina McCowan ${ }^{1 *}$ (D)

\begin{abstract}
Background: Canids are definitive hosts of the apicomplexan parasite Neospora caninum, the leading cause of abortion in cattle worldwide. For horizontal transmission from canids to occur, oocysts of N. caninum must be shed by the definitive host into the environment of susceptible intermediate hosts such as cattle. The purpose of this study was to determine the prevalence of $\mathrm{N}$. caninum in canids in Victoria, Australia's leading dairy producing state.

Results: Neospora-like oocysts were observed in 8\% (18/234) of faecal samples from wild dogs, domestic dogs and red foxes from Victoria, Australia. However, none tested positive for N. caninum DNA using a quantitative PCR. In a separate sample population, blood sera from 483 domestic dogs were tested for anti-N. caninum antibodies using competitive ELISA. A subset of cELISA samples were re-tested using indirect fluorescence antibody test (IFAT). A seroprevalence of $29.8 \%(144 / 483 ; 95 \%$ Cl: 11.7-47.8\%) was calculated when using CELISA; whereas it was 32.9\% (27/80; 95\% Cl: 15.8-51.8\%) using IFAT. Potential risk factors were evaluated using univariable analyses and then assessed in separate multivariable models. Using 'aged' dogs as a reference, the seroprevalence of 'adolescent' and 'adult' dogs was $88 \%(P=0.05)$ and $91 \%(P=0.08)$, respectively, indicating seroprevalence increases with age. There was a $19 \%$ higher likelihood of infection in rural locations $(P=0.10)$ relative to urban areas. Jack Russell Terriers had a 22\% higher risk of a cELISA-positive result $(P=0.05)$ regardless of geographical location, age or sex.

Conclusion: These results demonstrate that exposure to N. caninum in domestic dogs is widespread in Victoria, although faecal oocyst shedding is infrequent. Our results indicate increased $N$. caninum seroprevalance status in dogs over the past two decades. The results imply that dogs get either exposed to the infected meat more frequently or that vertical dam to foetus transmission is more frequent than previously thought. Our study calls for re-evaluation of historical $N$. caninum seroprevalance studies, because the attitude to dog diet changes.
\end{abstract}

Keywords: Neospora caninum, Epidemiology, Neosporosis, ELISA, IFAT, Dog, Canid, Fox, Seroprevalence

\section{Background}

Neospora caninum is an obligate intracellular, tissue cyst-forming, coccidian parasite regarded as the leading cause of abortion in cattle worldwide [1,2]. Canids - domestic and wild dogs (Canis lupus familiaris), grey wolves (Canis lupus), coyotes (Canis latrans) and dingoes (Canis lupus dingo) - are confirmed definitive hosts in which sexual reproduction of $N$. caninum

\footnotetext{
* Correspondence: christina.mccowan@ecodev.vic.gov.au

${ }^{1}$ Veterinary Pathobiology, Department of Economic Development, Jobs,

Transport and Resources, Bundoora, VIC, Australia

Full list of author information is available at the end of the article
}

occurs [3-5]. The life-cycle of N. caninum is maintained between canids and cattle, but there is often a concurrent sylvatic life-cycle between wild canids and herbivore species, particularly wild ruminants (e.g. deer) $[5,6]$.

Horizontal transmission is facilitated by the shedding of oocysts in the faeces of the definitive host which sporulate and are then infectious when ingested, the primary route of infection for canids [6-9]. Alternatively, carnivores may be infected by ingestion of tissue cysts in the flesh of noncarnivore species [9]. Infection in ruminants can occur vertically from the infected dam to her offspring, or 
horizontally via ingestion of $N$. caninum oocysts via the faecal contamination of food or water [10].

Very little is known about the impact of $N$. caninum in Victoria, Australia's leading dairy region. Australia is a major producer of agricultural products worldwide and the value of beef and milk production in 2015 was valued at $\$ 11.5$ billion and $\$ 4.7$ billion, respectively $[11,12]$. The economic impact of $N$. caninum-associated abortion in Australian cattle has been estimated to be more than $\$ 100$ million per year [13]. A study of N. caninum infection in dogs from Melbourne, Victoria, found a seroprevalence of $5 \%$ [14], but nothing has been done since then to determine the seroprevalence of Victorian dogs.

The primary objectives of this study were to determine the prevalence of oocyst shedding and seroprevalence of $N$. caninum in canids in Victoria, Australia. Oocyst shedding was evaluated using faecal flotations coupled with molecular diagnostics. Seroprevalence was evaluated using the competitive enzyme-linked immunosorbent assay (cELISA) and indirect fluorescence antibody test (IFAT). The data obtained enabled us to compare and contrast our data with those reported from 1997 [14]. Faecal and serological analyses of canids can help to identify at-risk locations and animal characteristics, therefore aiding in prevention of the spread of $N$. caninum and reducing its economic impact on the beef and dairy industries.

\section{Methods \\ Sample collection}

A single faecal sample per animal from wild dogs $(n=11)$ and red foxes $(n=188)$ was collected across Victoria, Australia (Fig. 1), by registered trappers and hunters during their normal hunting and trapping activities under Victorian legislation. A single faecal sample per animal from domestic dogs $(n=35)$ was collected by their respective owners or district veterinary officers, chilled $\left(4{ }^{\circ} \mathrm{C}\right)$, and sent in via direct post for faecal flotation analysis within 7 days from collection, where possible. The geographical location of sample collection and the age, sex and breed of each animal was recorded, where possible. In addition, dog serum samples $(n=488)$ were collected following the conclusion of laboratory testing from two veterinary diagnostic laboratories (Australian Specialised Animal Pathology; the Veterinary Teaching Hospital, The University of Melbourne) located in Victoria, including five samples from dogs located outside of Victoria: three from New South Wales, one from South

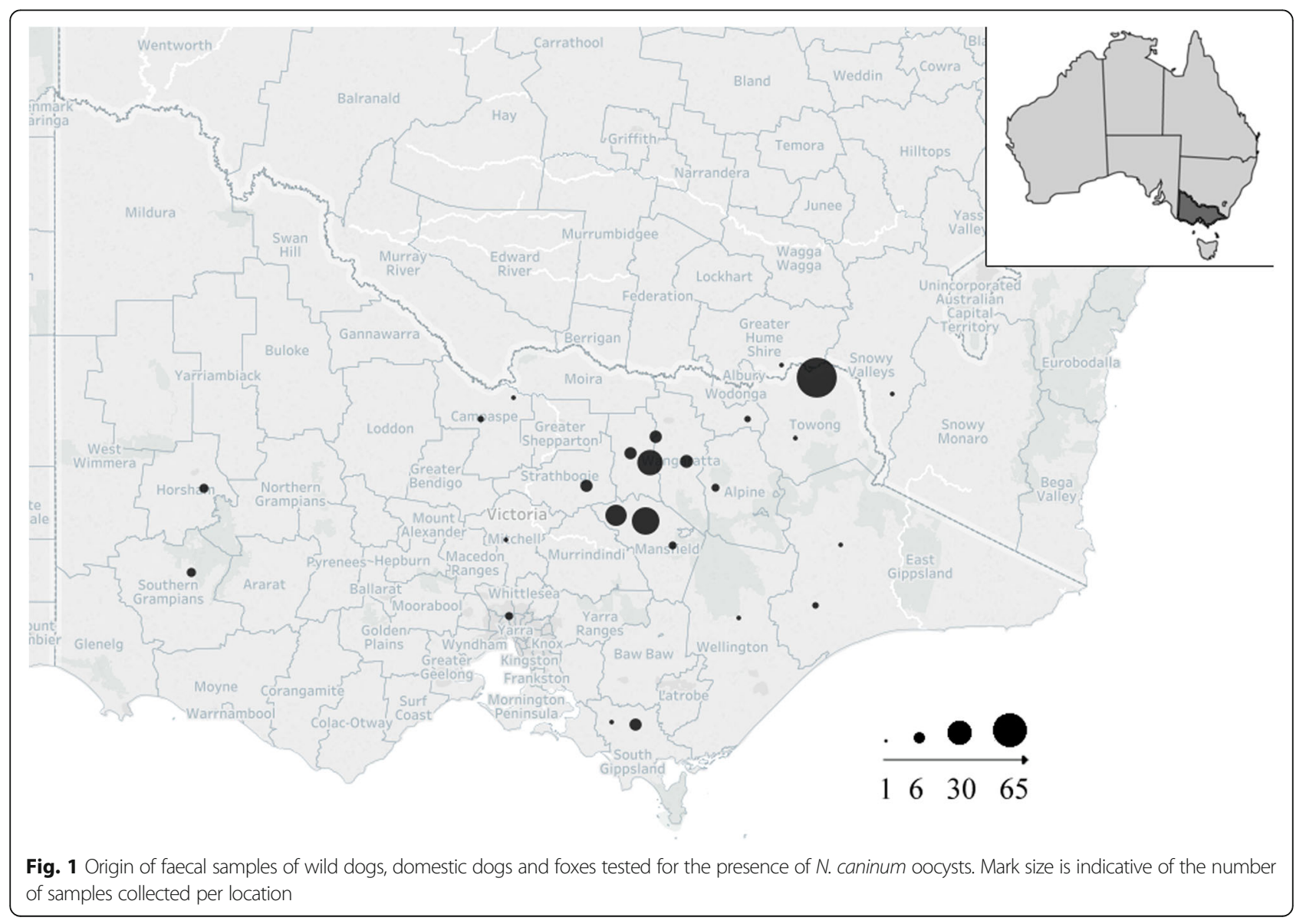


Australia and one from Tasmania. The home location, age, breed and sex of each animal was recorded for all samples. Of the non-Victorian samples, those from the mainland were all collected from sites adjacent to or straddling the state border.

\section{Faecal flotation}

A flotation solution was made using $375 \mathrm{~g} / \mathrm{l}$ of $\mathrm{NaCl}$ in water to create a solution with a specific gravity of 1.18 1.20 [15]. Faecal samples were examined microscopically for the presence of $N$. caninum-like oocysts $(10-15 \mu \mathrm{m}$ in diameter); oocysts of $N$. caninum/Hammondia spp. are shed unsporulated, unlike those of Sarcocystis spp., but, due to the time between excretion and examination, during which sporulation could have occurred, we included samples with unsporulated oocysts or with oocysts containing two sporocysts each with four sporozoites. The top layer of the flotation solution supernatant was transferred to a $15 \mathrm{ml}$ tube, topped up with water and centrifuged at $1670 \times g$ for $5 \mathrm{~min}$ to create a pellet. The tube was stored at $-20{ }^{\circ} \mathrm{C}$ until required for DNA extraction.

\section{DNA extraction and PCR}

Stored faecal flotation samples from above $(n=179)$ were defrosted at room temperature $\left(23 \pm 2{ }^{\circ} \mathrm{C}\right)$ and centrifuged at $3220 \times g$ for $15 \mathrm{~min}$ and the pellet $(<$ $200 \mathrm{mg}$ ) used for DNA isolation. All samples that were positive on flotation and a selection of negative samples were tested. DNA was extracted using a PowerSoil DNA Isolation Kit (MO BIO Laboratories, Carlsbad, CA, USA) following the manufacturer's instructions with some modifications: the PowerBead Tubes were secured horizontally in a TissueLyser II (Qiagen, Hilden, Germany) and vortexed for $30 \mathrm{~s}$ at $30 \mathrm{~Hz}$, and tubes were centrifuged at $10,000 \times g$ for $1 \mathrm{~min}$ for all steps requiring centrifugation. The DNA samples were eluted to $100 \mu \mathrm{l}$ and stored at $-20{ }^{\circ} \mathrm{C}$ until required for analysis by quantitative PCR.

Quantitative PCR (qPCR) was used to determine whether the $N$. caninum spp.-like oocysts observed in the faecal flotations were effectively $N$. caninum and not species in closely related coccidian genera like Sarcocystis, Hammondia and Toxoplasma. The primers and probe, targeting the Nc5 locus, a repetitive sequence present in the $N$. caninum genome, were based on those developed by Ghalmi et al. [16]. These primers and probes were checked for suitability using MEGA7 Alignment Explorer software (www.megasoftware.net). An error in the published reverse primer sequence was identified; a $G$ at position 7. The updated primers and probe used in this study were NC5-550-F: $5^{\prime}$-GGG TGA ACC GAG GGA GTT G-3'; NC5-596-R: 5' -ACG TGA CGA ATG ACT AAC CAC AA-3'; NC5 probe: 5'6FAM-AGC GGT GAG AGG TGG GAT ACG TGG-
TAMRA-3'. A primer/probe mix was made with $10 \mu \mathrm{l}$ of forward primer $(10 \mu \mathrm{M}), 10 \mu \mathrm{l}$ of reverse primer $(10 \mu \mathrm{M}), 3 \mu \mathrm{l}$ of probe $(3 \mu \mathrm{M})$, and $77 \mu \mathrm{l}$ of nucleasefree water. An $18 \mathrm{~S}$ rRNA extraction control (TaqMan ${ }^{\circ}$ Ribosomal RNA Control Reagents; Applied Biosystems, Foster City, CA, USA) was used to ensure correct extraction of sample DNA and RNA. Using AgPath-ID One-Step RT-PCR Reagents (Applied Biosystems), $5 \mu \mathrm{l}$ of sample-extracted DNA was mixed with $12.5 \mu \mathrm{l}$ of $2 \mathrm{X}$ RT-PCR buffer, $1 \mu \mathrm{l}$ of primer/probe mix, $1 \mu$ l of enzyme, $0.375 \mu \mathrm{l}$ of $18 \mathrm{~S} \mathrm{rRNA}$ primer/probe mix (1:1:1) and $5.125 \mu \mathrm{l}$ of nuclease-free water, as per the manufacturer's instructions. Samples then underwent the following thermocycling programme in a 7500 Fast Real-Time PCR System (Applied Biosystems): $1 \times\left(50{ }^{\circ} \mathrm{C}\right.$ for $\left.2 \mathrm{~min}\right)$, $1 \times\left(95{ }^{\circ} \mathrm{C}\right.$ for $\left.10 \mathrm{~min}\right)$, and $50 \times\left(95^{\circ} \mathrm{C}\right.$ for $15 \mathrm{~s}, 58{ }^{\circ} \mathrm{C}$ for $1 \mathrm{~min}$ ) as per Ghalmi et al. [16]. All samples were run in duplicate. A no-template sample served as negative control, and $N$. caninum WA-K9 DNA in 1:10,000 and 1:100,000 dilutions was used as positive control (original concentration $100 \mathrm{ng} / \mu \mathrm{l}$ ).

In addition, for flotation-positive samples, the apicomplexan D2 domain of the large subunit (LSU) rRNA gene was amplified using the CR1-CR2 primer pairs as published previously [17-19], MyTaq ${ }^{\text {Tw }}$ Red Mix (Bioline Australia, Alexandria, NSW, Australia) and $2 \mu \mathrm{l}$ of sample DNA in $25-\mu \mathrm{l}$ reactions, with included controls, as described previously [20]. PCR products ( $600 \mathrm{bp})$ were sequenced (Macrogen, Seoul, South Korea) and the resulting DNA sequences visually inspected for ambiguity and aligned with the homologous sequences from related cyst-forming coccidia (genera Sarcocystis, Neospora, Toxoplasma, Cystoisospora, Hammondia, Besnoitia) using CLC Main Workbench v6.9.1 (CLC bio, Aarhus, Denmark).

\section{Statistical analysis of faecal data}

A backwards stepwise model-building process was used to develop a logistic regression model at the animal level, with variables retained if they were associated with $P \leq 0.05$, derived from a likelihood-ratio test (RStudio packages nlme and lme4; RStudio, Boston, MA, USA). Potential risk factors evaluated were animal 'type' (fox, domestic dog, wild dog), sex (male, female), age (adolescent, adult, aged) and geographical location. Location was split into seven Victorian local government areas (LGAs): Benalla, Gippsland, Horsham, Hume, Mansfield, Towong and Wellington. Any locations situated outside of the boundaries of these LGAs were assigned to the geographically closest LGA. Results are presented as odds ratios and significance indicated using $P$-values.

\section{Competitive ELISA}

Using the methodology previously described [21, 22], dog serum samples $(n=483)$ were screened for anti- $N$. 
caninum antibodies using a $N$. caninum Antibody Test Kit - cELISA (VMRD, Pullman, WA, USA) that was previously validated for use in cattle and partially validated for use in dogs [22-24]. Absorbance spectrophotometry was used to measure the percentage inhibition (\%I) of colour change. The $\% \mathrm{I}$ is the rate at which colour development is prevented, indicating a positive result. Sera were considered positive for anti- $N$. caninum antibodies when samples presented the manufacturer's recommended \%I cut-off of $>30 \%$, a threshold validated for cattle.

\section{Indirect fluorescence antibody test}

Competitive ELISA $N$. caninumpositive $(n=39)$ and 40 negative $(n=41)$ dog serum samples were re-tested for the presence of anti- $N$. caninum antibodies using an indirect fluorescence test (IFAT). As in previous studies $[11,25,26]$, IFAT tachyzoite $N$. caninum 12 -well slides, FITC anti-canine serum, $N$. caninum canine positive serum and $N$. caninum canine negative serum (all from VMRD) were used according to the manufacturer's instructions. Slides were examined with an Olympus BX60 microscope equipped to detect fluorescein isothiocyanate fluorescence (FITC, maximum excitation wavelength $490 \mathrm{~nm}$; mean emission wavelength $530 \mathrm{~nm}$ ). Under fluorescent light, the positive controls showed bright green banana-shaped tachyzoites of $N$. caninum, 4 to $5 \mu \mathrm{m}$ in length. A sample was considered positive if complete peripheral tachyzoite labelling for anti-N. caninum antibodies was observed following a serum dilution of 1:50 (VMRD, manufacturer's recommendation).

\section{Statistical analysis of serum data}

Potential risk factors were assessed using univariable analyses and then, if significant $(P \leq 0.20)$, in separate multivariable models. A backwards stepwise modelbuilding process was used to develop a logistic regression model at the animal level, with variables retained if $P \leq 0.05$, derived from a likelihood-ratio test (RStudio). Biologically plausible interaction terms between maineffects variables were then considered for inclusion in the multivariable model. Summary measures of model goodness-of-fit included comparison of deviance to the degrees of freedom and Pearson $\chi^{2}$ statistics. Results are presented as odds ratios and significance indicated using $P$-values, with statistical significance confirmed at $P<0.05$. $P$-values of $<0.10$ were indicated, where appropriate, to demonstrate where the result approached statistical significance.

Risk factors evaluated were sex (male, female), breed (categorised into small, medium, large; and categorised into the breed groupings of gundog, hound, utility, working, terrier, toy, non-sporting) and age ('puppy', s 2 years old; 'adolescent', $2-5$ years old; 'adult', $6-12$ years old; 'aged', > 12 years old). In addition, the geographical location of each animal was categorised into either urban (metropolitan Melbourne and Geelong) or rural (all other locations). The urban category was further divided into 17 LGAs to evaluate this variable in more detail. The significance of selected individual breeds and their crosses (i.e. those with $\geq 10$ animals in the study population: Jack Russell Terrier, Labrador Retriever, Border Collie, German Shepherd, Chihuahua, Maltese Terrier, Cavalier King Charles Spaniel, Staffordshire Bull Terrier and Kelpie), relative to all other breeds in the study population.

A Two-Graph Receiver Operating Characteristic (TGROC) was developed using the IFAT results as a reference to analyse the sensitivity and specificity of the ELISA at \%I cut-off points increasing at 5\% intervals from 0 to $100 \%$.

\section{Results}

Presence of $N$. caninum-like oocysts in faecal samples Of the 234 canid faecal samples, 18 samples (two of domestic dogs, one of a wild dog and 15 of foxes) contained oocysts matching the morphological characteristics of $N$. caninum spp--like oocysts (Table 1). These oocysts measured approximately $11( \pm 3) \mu \mathrm{m}$ in diameter. Quantitative PCR was performed on 179 samples that either contained suspected oocysts $(n=18)$ or not $(n=161)$. While the 18S RNA extraction control could be amplified in all samples, none of the samples showed amplification of $N$. caninum genomic DNA. There were no significant associations between a faecal flotation-positive result for $N$. caninum and assessed potential risk factors, including animal type, age, sex or geographical location $(P>0.05)$.

To determine the identity of the oocyst-like structures found in fox and dog faeces, we used a PCR reaction with primers that preferentially amplified DNA of cyst-forming coccidia (genera Sarcocystis, Neospora, Toxoplasma, Cystoisospora, Hammondia and Besnoitia) [17, 18, 27]. Twenty-four samples (of which five were from outside Victoria) containing oocyst-like structures were selected and $83 \%(20 / 24)$ produced a PCR amplicon of a size recognised as coccidian. Ten amplicons were of sufficient quantity for direct DNA sequencing. Seven PCR products produced a DNA sequence of satisfactory quality that, in each case, was near identical (>99\%) to Sarcocystis tenella D2 LSU rDNA (AF076899).

\section{Presence of anti- $N$. caninum antibodies in serum samples}

Sera from domestic dogs were first assayed using cELISA for the detection of anti- $N$. caninum antibodies. Of the samples from Victorian dogs, 29.8\% (144/483; 95\% CI: $11.7-47.8 \%)$ tested positive for $N$. caninum antibodies using the manufacturer's suggested \%I cut-off of $>30 \%$. Table 2 shows associations between animal level 
Table 1 Presence of Neospora caninum oocysts in faecal samples of canids in Victoria, Australia

\begin{tabular}{llllll}
\hline Origin of samples & \multicolumn{2}{l}{ Neospora-like oocysts observed in faeces } & & Positive Nc5 qPCR on oocysts \\
\cline { 2 - 5 } & Foxes & Domestic dogs & Wild dogs & Total (\%) & $0 / 54$ \\
\hline Benalla & $2 / 51(4 \%)$ & $0 / 2(0 \%)$ & $1 / 5(20 \%)$ & 5 & $0 / 3$ \\
Gippsland & $0 / 1(0 \%)$ & $0 / 8(0 \%)$ & $0 / 1(0 \%)$ & 0 & $0 / 3$ \\
Horsham & - & $1 / 9(11 \%)$ & - & 11 & $0 / 6$ \\
Hume & - & $1 / 6(17 \%)$ & $0 / 1(0 \%)$ & 14 & $0 / 45$ \\
Mansfield & $4 / 55(7 \%)$ & $0 / 1(0 \%)$ & - & 7 & $0 / 53$ \\
Towong & $7 / 73(10 \%)$ & $0 / 7(0 \%)$ & - & 9 & $0 / 6$ \\
Wellington & $0 / 1(0 \%)$ & $0 / 2(0 \%)$ & $0 / 4(0 \%)$ & 0 & $0 / 9$ \\
Unknown location & $2 / 7(29 \%)$ & - & - & 29 & $0 / 179$ \\
Total & $15 / 188(8 \%)$ & $2 / 35(6 \%)$ & $1 / 11(9 \%)$ & 8 &
\end{tabular}

risk factors and a positive cELISA result for N. caninum in Victorian domestic dogs. Although breed, when divided into groups (Additional file 1: Table S1), was not significantly associated with $N$. caninum infection $(P>0.05)$, Jack Russell Terriers had a $22 \%$ higher risk of $N$. caninum infection $(P=0.05)$, regardless of geographical location, age or sex, when compared to the other breeds in the study population. Although the Border
Collie breed was significantly associated with an cELISA-positive result in the univariable analysis, this could not be replicated in the multivariable analysis. The likelihood of an adolescent or adult dog being infected with $N$. caninum was $88 \%(P=0.05)$ and $91 \%(P=0.08)$, respectively, of the likelihood of an aged dog. However, puppy infection rates closely resembled (97\%) those of aged dogs, the reference group. Furthermore, there was

Table 2 Potential risk factors for Victorian domestic dogs tested positive for Neospora caninum antibodies by cELISA

\begin{tabular}{|c|c|c|c|c|c|c|c|}
\hline Risk factor & & $\beta$ & SE $(\beta)$ & $P$ & OR & $\mathrm{LCl}$ & $\mathrm{UCl}$ \\
\hline Breed & Jack Russell Terrier & 0.20 & 0.10 & $0.05^{*}$ & 1.22 & 1.02 & 1.43 \\
\hline \multirow[t]{4}{*}{ Age } & Aged (12+ years) & Ref & - & - & Ref & - & - \\
\hline & Adult (6-12 years) & -0.10 & 0.06 & 0.08 & 0.91 & 0.80 & 1.02 \\
\hline & Adolescent ( $2-5$ years) & -0.13 & 0.07 & $0.05^{*}$ & 0.88 & 0.75 & 1.01 \\
\hline & Puppy (1-2 years) & -0.03 & 0.09 & 0.71 & 0.97 & 0.80 & 1.14 \\
\hline \multirow[t]{17}{*}{ Geographical location } & Rural & Ref & - & - & Ref & - & - \\
\hline & Bayside & -0.01 & 0.18 & 0.97 & 0.99 & 0.64 & 1.35 \\
\hline & Boroondara & -0.27 & 0.13 & $0.04^{*}$ & 0.76 & 0.50 & 1.02 \\
\hline & Brimbank & -0.28 & 0.11 & $0.01^{*}$ & 0.75 & 0.54 & 0.97 \\
\hline & Cardinia & 0.11 & 0.15 & 0.44 & 1.12 & 0.83 & 1.41 \\
\hline & Frankston & -0.17 & 0.17 & 0.31 & 0.84 & 0.51 & 1.17 \\
\hline & Glen Eira & -0.02 & 0.13 & 0.91 & 0.99 & 0.73 & 1.25 \\
\hline & Greater Dandenong & 0.08 & 0.13 & 0.56 & 1.08 & 0.82 & 1.34 \\
\hline & Greater Geelong & -0.23 & 0.13 & 0.08 & 0.80 & 0.54 & 1.05 \\
\hline & Hobsons Bay & -0.13 & 0.13 & 0.31 & 0.87 & 0.62 & 1.13 \\
\hline & Macedon Ranges & -0.05 & 0.16 & 0.77 & 0.96 & 0.65 & 1.26 \\
\hline & Moreland & -0.13 & 0.19 & 0.50 & 0.88 & 0.51 & 1.25 \\
\hline & Melbourne City & -0.12 & 0.13 & 0.34 & 0.89 & 0.64 & 1.13 \\
\hline & Whitehorse & -0.22 & 0.15 & 0.14 & 0.80 & 0.51 & 1.09 \\
\hline & Whittlesea & -0.13 & 0.16 & 0.44 & 0.88 & 0.57 & 1.20 \\
\hline & Yarra & -0.20 & 0.15 & 0.19 & 0.82 & 0.51 & 1.12 \\
\hline & Yarra Ranges & -0.22 & 0.15 & 0.15 & 0.81 & 0.51 & 1.10 \\
\hline
\end{tabular}

Abbreviations: $\beta$ beta coefficient, $L C l$ lower confidence interval, OR odds ratio, Ref reference point, $S E(\beta)$ standard error of the beta co-efficient, UCI upper confidence interval

*P $\leq 0.05$ 
a 19\% higher likelihood of $N$. caninum infection in rural versus urban domestic dogs $(P=0.10)$. When assessed at the LGA level, dogs from two LGAs, Brimbank $(P=0.01)$ and Boroondara $(P=0.04)$ (Additional file 2: Figure S1), had a lower likelihood of $N$. caninum infection relative to those from rural locations. The remaining risk factors, breed (small, medium and large) and sex, were not significantly associated with an ELISA-positive result for $N$. caninum $(P>0.05)$.

A selection of 39 cELISA-positive and 41 cELISAnegative samples was re-tested using IFAT to compare the $N$. caninum infection status of the dogs between these two tests. Among the (in total) 27 IFAT-positive dogs, only 18 were also found positive by cELISA, with 9 dogs presenting as cELISA false negatives. Among the 53 IFAT-negative dog sera, 23 tested positive using cELISA (Table 3). The sensitivity (Se) and specificity (Sp) of the cELISA at the 30\%I cut-off were calculated to be 66.7 and $57.0 \%$, respectively. The results of the cELISA and IFAT were analysed using TG-ROC to compare the Se and Sp of the cELISA at different \% I cut-off points, increasing in intervals of $5 \%$ (Fig. 2). Se and $\mathrm{Sp}$ were equal (62\%) at a \% cut-off of $31.5 \%$.

\section{Discussion}

The calculated seroprevalence of $N$. caninum in Victoria determined by competitive enzyme-linked immunosorbent assay (cELISA) and indirect fluorescence antibody test (IFAT) was 29.8\% (144/483; 95\% CI: $11.7-47.8 \%)$ and $32.9 \%$ (27/80; 95\% CI: $15.8-51.8 \%)$, respectively. The high IgG seroprevalence > 25\% was unexpected, because a previous seroprevalence study on domestic dogs; urban, semiurban, rural, and euthanased at animal shelters, all domiciled in Melbourne, Victoria $(n=207)$ were tested using IFAT and the overall seroprevalence demonstrated only 5\% (95\% CI: 2-9\%) of dogs positive for anti-N. caninum IgG antibodies in 1997 [14] and 9\% (42/451; 95\% CI: 6-12\%) in Australia overall. A more recent study using sera from Aboriginal community dogs demonstrated $N$. caninum seroprevalence of $23.2 \%$ (45/ 194; 95\% CI: $17.8-29.7 \%)$ and 20.6\% (40/194; 95\% CI: 15.5-26.9\%) using cELISA and IFAT, respectively [22]. It was speculated, that the high $N$. caninum seroprevalence

Table 3 Overall comparison of IFAT and cELISA results for the detection of anti-Neospora caninum antibodies in serum of Victorian domestic dogs

\begin{tabular}{lllll}
\hline & & IFAT & & \\
\cline { 3 - 5 } & & + & - & Total \\
\hline CELISA 30\%l & + & 18 & 23 & 41 \\
& - & 9 & 30 & 39 \\
& Total & 27 & 53 & 80 \\
\hline
\end{tabular}

Abbreviations: CELISA 30\%/ competitive enzyme-linked immunosorbent assay $30 \%$ inhibition cut-off, IFAT indirect fluorescence antibody test compared to urban dogs is caused by the scavenging behaviour of the examined dogs and consumption of wild animals suggestive of a sylvatic $N$. caninum cycle $[5,6,22]$. The even higher seroprevalence than Aboriginal community dogs detected in our study, suggests that opportunity for $N$. caninum infection is high in urban areas such as Melbourne, Victoria. The rather dramatic shift in seroprevalence from $5 \%$ to approximately $30 \%$ is potentially alarming, because of the consequences of clinical neosporosis in dogs [28, 29].

High seroprevalence in dog populations ultimately leads to increased vertical transmission from mother to foetus maintaining the parasite within the dog population [30]. In our study, puppies had a significantly greater seroprevalence than both adolescent and adult dogs; we speculate that thismay indicate a recent increase of seropositivity of pregnant bitches in the area, hence vertical transmission as well as post-weaning horizontal transmission and thatthe reason for the increased $N$. caninum seroprevalence could mean that, compared to the 1990s, the attitudes of dog owners to dogs' diets have changed. In the past, dry processed food may have been more acceptable to pet owners, unlike now, where supplementing raw meat and bones into dogs' diets is increasing. However, further studies are required to understand the reasons behind the $30 \% \mathrm{~N}$. caninum seroprevalence. Horizontal (feeding infected meat) transmission of $N$. caninum is supported by increase in seroprevalance with age; however, there was greater seropositivity in rural than urban locations. There were clear differences within the metropolitan area of Melbourne that may reveal different attitudes and practices of dog owners. The finding that Jack Russell Terriers were 22\% more likely to have $N$. caninum infection regardless of location, sex or age is valuable, but further studies are required to determine and confirm breed susceptibility to $N$. caninum.

In the current study, there were no confirmed $N$. caninum oocysts observed in the faeces of 179 Victorian canids. Faecal flotation can be used to isolate $N$. caninum oocysts shed in faeces and to determine the prevalence of neosporosis in a population [4, 22, 31]. However, N. caninum oocysts are morphologically indistinguishable from closely related genera, such as Toxoplasma and Hammondia. Therefore, genetic analysis of oocysts by PCR is required for confirmation [5, 25]. Exposure of both intermediate and definitive hosts to $N$. caninum is commonly evaluated using IFAT $[16,26]$ or ELISA $[5,32]$ to detect anti-N. caninum antibodies in serum. Despite its subjectivity, which is dependent on user observation of fluorescence, IFAT is currently considered the 'gold standard' for canine N. caninum serology, because it shows virtually no cross-reactivity with related protozoan parasites [2, 33, 34].

The $N$. caninum-like oocysts observed in faecal samples of several foxes, two domestic dogs and one wild dog were shown to be Sarcocystis tenella, a coccidian 


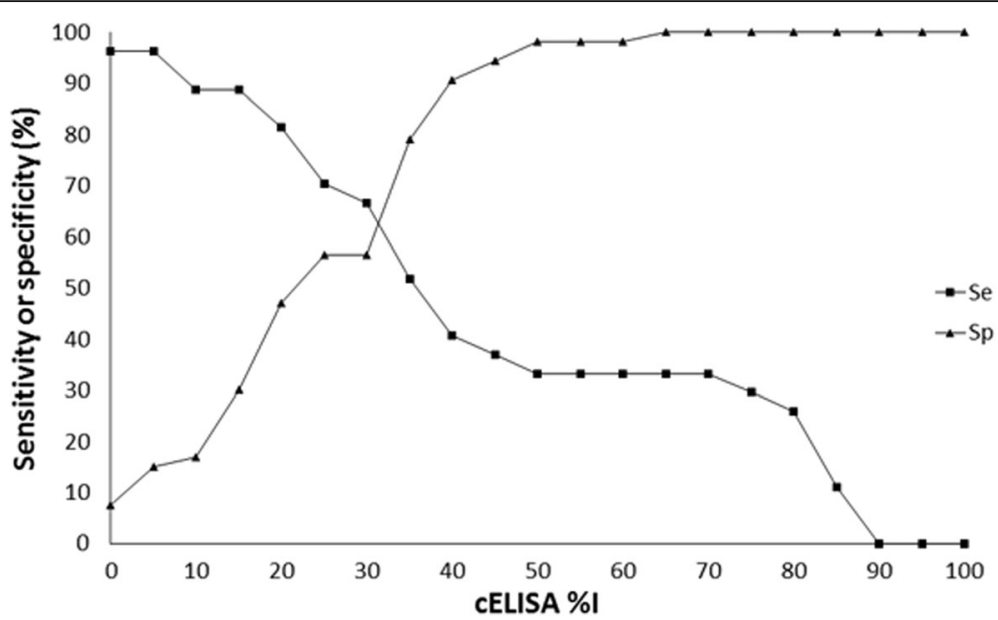

Fig. 2 Two-graph receiver operating characteristic analysis of ELISA results against IFAT results. Key: squares: sensitivity (Se); triangles: specificity (Sp)

with a sheep-canid life-cycle, and known to be carried by foxes $[25,35]$, following further investigation where sufficient material was available. Identification of $N$. caninum oocysts is known to be difficult because of their morphological similarities to other coccidian genera. In addition, the shedding time-frame ranges from 1 day to several weeks $[7,36,37]$, and the quantity of oocysts varies per sample $[38,39]$. Despite the lack of $N$. caninum oocyst-shedding observed in this study, $N$. caninum-associated abortion in cattle is still occurring in Victoria with three confirmed abortion outbreaks this year and several more in the preceding years until 2012 (K. Moore, DEDJTR, pers. comm.). One sample from a domestic dog residing on a farm that was experiencing a $N$. caninum-associated outbreak of abortion at the time of sampling also tested negative. Epidemic abortion outbreaks are associated with point-source horizontal transmission to cattle [5, 40], which occur naturally via ingestion of canid-shed oocysts. The number of abortion outbreaks on Victorian farms from 2012 to 2016 indicate that, while shedding was not detected in this study, it is consistently occurring in the environment. The lack of obvious N. caninum shedding does not necessarily indicate its absence. Infected dogs may shed oocysts for short periods of time only, and factors influencing recurrence of shedding are poorly understood. Survival of oocysts in the environment is enhanced by a number of factors including immunosuppression [30]. Very little is known about the survival of $N$. caninum oocysts in the environment, however, it is assumed their environmental resistance is similar to that of $T$. gondii oocysts [30]. The year of this study may have had conditions that do not favour N. caninum oocyst-shedding or spread. There were indeed fewer confirmed $N$. caninum-associated abortions this year than in the previous few years (K. Moore, DEDJTR, pers. comm.).
The role of foxes in the transmission of $N$. caninum remains controversial, with one study identifying oocysts in faeces [31], but experimental transmission being unsuccessful [41]. The identification of $N$. caninum oocysts in fox faeces in a previous study may have been due to the ingestion of infective material containing tissue cysts and this may be the cause for positive amplification in some faecal samples [31]. Foxes are known definitive hosts of S. tenella as well as Hammondia triffitae, the oocysts of which resemble those of $N$. caninum [42].

IFAT is currently considered the gold standard for canine $N$. caninum serology $[2,34]$, and has been used since the early days of serological detection of this parasite [33]. IFAT is a subjective technique that relies on the experience of the individual analysing the samples, and is not quantifiable. The cELISA is a more recently developed method, and is objective and quantifiable. However, the cELISA kit used in this study was developed for use in cattle and may not use optimal reagents for detection of canine immunoglobulins. Partial validation of the cELISA kit found a naïve Se and Sp of 72 and $89 \%$, respectively, and a corrected Se and Sp of 47 and $72 \%$, respectively, at the 30\%I cELISA cut-off for canine serum [24]. Similarly, King et al. [22] calculated a Se and Sp of 45 and 82\%, respectively, at the 30\%I cELISA cut-off. These numbers are slightly better than those calculated in the current study, but show that the low Se and Sp was expected.

It is time to reconsider the gold standard for $N$. caninum serology in canines because of the subjectivity of IFAT and the difficulty in using this technique for large numbers of samples. If ELISA is chosen as the new gold standard, it would need to be validated with a caninespecific antibody [43-45]. The above assessment of Se and Sp of the cELISA assumes that the IFAT had 100\% $\mathrm{Se}$ and $\mathrm{Sp}$. As indicated above, due to the subjective 
nature of this test, this assumption is likely false and statistical analyses that determine test Se and $\mathrm{Sp}$ in the absence of a gold standard (e.g. latent class analysis, Bayesian analysis) are required to determine the true $\mathrm{Se}$ and Sp of both the IFAT and cELISA in the diagnosis of $N$. caninum in this population.

\section{Conclusion}

Effective prevention of spread of neosporosis in both bovine and canine populations can only be developed and implemented if transmission of $N$. caninum is fully understood. This study indicates that there is widespread infection among domestic canids despite a lack of shedding observed, and even farms with known $N$. caninum outbreaks have undetectable oocyst-shedding from the resident domestic dogs. The six-fold increase of seroprevalence in the canine population over 20 years indicates new transmission routes and behaviours of dog owners that require further elucidation. Our study demonstrates that data obtained 20 years ago can be misleading and current studies remain vital in understanding disease that cause significant burden to farm animals.

\section{Additional files}

Additional file 1: Table S1. Evaluation of the association of potential risk factors for a domestic dog tested positive for Neospora caninum antibodies by univariable analysis. (DOCX $18 \mathrm{~kb}$ )

Additional file 2: Figure S1. Location map of Metropolitan Melbourne, Victoria, Australia showing local government area names. C, City Council; S, Shire Council. (PNG $130 \mathrm{~kb}$ )

\section{Abbreviations}

\%l: Percentage of inhibition; CELISA: Competitive enzyme-linked immunosorbent assay; Cl: Confidence interval; IFAT: Indirect fluorescence antibody test; LGA: Local government area; qPCR: Quantitative polymerase chain reaction

\section{Acknowledgements}

The authors wish to thank the district veterinary officers, farmers and pest controllers for collecting and sending in faecal samples, particularly Dr. Ian Holmes, Dr. Will Hume, Peter White, L Collins, Lachlan King, Dr. Amy Sluggett, Dr. Ash Phipps, Dr. John Ryan and Dr. Jeff Cave; Dr. Dieter Palmer, Department of Agriculture and Food, Western Australia, for providing N. caninum WA-K9 DNA; Christine Andersen, Dr. Tonya Weichel, Kim O'Riley, Dr. Mark Fegan and Dr. Andrea Casteriano for technical advice; the Veterinary Teaching Hospital, The University of Melbourne and Australian Specialised Animal Pathology Laboratory for donations of serum.

\section{Funding}

This study was supported by internal funding from the Department of Physiology, Anatomy and Microbiology, La Trobe University.

\section{Availability of data and materials}

The datasets supporting the conclusions of this article are included within the article and its additional files.

\section{Authors' contributions}

SS contributed to the acquisition, analysis, and interpretation of data, and drafted the manuscript. JŠ contributed to the acquisition, analysis, and interpretation of data, and critically revised the manuscript. AJ contributed to the conception and design of the study and critically revised the manuscript.
$\mathrm{JH}$ contributed to the analysis of data and critically revised the manuscript. BDG contributed to the conception of the study and critically revised the manuscript. GR contributed to the conception of the study. CM contributed to the conception and design of the study and critically revised the manuscript. All authors read and approved the final manuscript.

Ethics approval and consent to participate

This study was approved by the Animal Ethics Committee of La Trobe University (AEC16-28)

Consent for publication

Not applicable.

\section{Competing interests}

The authors declare that they have no competing interests.

\section{Publisher's Note}

Springer Nature remains neutral with regard to jurisdictional claims in published maps and institutional affiliations.

\section{Author details}

${ }^{1}$ Veterinary Pathobiology, Department of Economic Development, Jobs, Transport and Resources, Bundoora, VIC, Australia. ${ }^{2}$ Department of Physiology, Anatomy and Microbiology, School of Life Sciences, La Trobe University, Bundoora, VIC, Australia. ${ }^{3}$ Sydney School of Veterinary Science, Faculty of Science, The University of Sydney, Sydney, NSW, Australia. ${ }^{4}$ Faculty of Veterinary and Agricultural Sciences, The University of Melbourne, Werribee, VIC, Australia. ${ }^{5}$ Agriculture and Resource Division, Department of Economic Development, Jobs, Transport and Resources, Bundoora, VIC, Australia.

Received: 8 May 2017 Accepted: 9 October 2017

Published online: 19 October 2017

\section{References}

1. Dubey JP, Buxton D, Wouda W. Pathogenesis of bovine neosporosis. J Comp Pathol. 2006:134:267-89.

2. Hemphill A, Gottstein B. A European perspective on Neospora caninum. Int J Parasitol. 2000:30:877-924.

3. Basso W, Venturini L, Venturini MC, Hill DE, Kwok OC, Shen SK, Dubey JP. First isolation of Neospora caninum from the feces of a naturally infected dog. J Parasitol. 2001:87:612-8.

4. King JS, Šlapeta J, Jenkins DJ, Al-Qassab SE, Ellis JT, Windsor PA. Australian dingoes are definitive hosts of Neospora caninum. Int J Parasitol. 2010;40:945-50.

5. Donahoe SL, Lindsay SA, Krockenberger M, Phalen D, Šlapeta J. A review of neosporosis and pathologic findings of Neospora caninum infection in wildlife. Int J Parasitol Parasites Wildl. 2015;4:216-38.

6. King JS, Jenkins DJ, Ellis JT, Fleming P. Windsor PA, Šlapeta J. Implications of wild dog ecology on the sylvatic and domestic life cycle of Neospora caninum in Australia. Vet J. 2011;188:24-33.

7. Gondim LFP, Gao L, McAllister MM. Improved production of Neospora caninum oocysts, cyclical oral transmission between dogs and cattle, and in vitro isolation from oocysts. J Parasitol. 2002;88:1159-63.

8. Gondim LF, McAllister MM, Gao L. Effects of host maturity and prior exposure history on the production of Neospora caninum oocysts by dogs. Vet Parasitol. 2005;134:33-9.

9. Lindsay DS, Ritter DM, Brake D. Oocyst excretion in dogs fed mouse brains containing tissue cysts of a cloned line of Neospora caninum. J Parasitol. 2001:87:909-11.

10. Radostits OM, Gay C. Neosporosis. In: Radostits OM, Gay CC, Hinchcliff KW, Constable PD, editors. Veterinary medicine: a textbook of the diseases of cattle, sheep, pigs, goats, and horses. 10th ed. New York: Elsevier Saunders; 2007. p. 1509-12.

11. Anon. Australian Dairy Industry in Focus 2015. In: Australian Dairy Industry in Focus. Dairy Australia. 2015. https://www.dairyaustralia.com.au/publications/ australian-dairy-industry-in-focus-2016. Accessed 06 Aug 2016.

12. Australian Bureau of Statistics. Value of Agricultural Commodities Produced, Australia, 2014-15 data. 2016. http://www.abs.gov.au/ausstats/abs@.nsf/mf/ 7503.0. Accessed 05 Aug 2016.

13. Reichel MP. Neospora caninum infections in Australia and New Zealand. Aus Vet J. 2000;78:258-61. 
14. Barber JS, Gasser RB, Ellis J, Reichel MP, McMillan D, Trees AJ. Prevalence of antibodies to Neospora caninum in different canid populations. J Parasitol. 1997;83:1056-8.

15. Dryden MW, Payne PA, Ridley R, Smith V. Comparison of common fecal flotation techniques for the recovery of parasite eggs and oocysts. Vet Ther. 2005;6:15-28.

16. Ghalmi F, China B, Kaidi R, Daube G, Losson B. Detection of Neospora caninum in dog organs using real time PCR systems. Vet Parasitol. 2008;155:161-7.

17. Ellis JT, Amoyal G, Ryce C, Harper PA, Clough KA, Homan WL, Brindley PJ. Comparison of the large subunit ribosomal DNA of Neospora and Toxoplasma and development of a new genetic marker for their differentiation based on the D2 domain. Mol Cell Probes. 1998;12:1-13.

18. Šlapeta J, Modry D, Votypka J, Jirku M, Lukes J, Koudela B. Evolutionary relationships among cyst-forming coccidia Sarcocystis spp. (Alveolata: Apicomplexa: Coccidea) in endemic African tree vipers and perspective for evolution of heteroxenous life cycle. Mol Phylogenet Evol. 2003;27:464-75.

19. Cooper MK, Phalen DN, Donahoe SL, Rose K, Šlapeta J. The utility of diversity profiling using Illumina $18 \mathrm{~S}$ rRNA gene amplicon deep sequencing to detect and discriminate Toxoplasma gondii among the cyst-forming coccidia. Vet Parasitol. 2016;216:38-45.

20. Donahoe SL, Rose K, Šlapeta J. Multisystemic toxoplasmosis associated with a type II-like Toxoplasma gondii strain in a New Zealand fur seal (Arctocephalus forsteri) from new South Wales, Australia. Vet Parasitol. 2014;205:347-53.

21. Moreno-Torres K, Wolfe B, Saville W, Garabed R. Estimating Neospora caninum prevalence in wildlife populations using Bayesian inference. Ecol Evol. 2016;6:2216-25.

22. King JS, Brown GK, Jenkins DJ, Ellis JT, Fleming PJ, Windsor PA, Šlapeta J. Oocysts and high seroprevalence of Neospora caninum in dogs living in remote aboriginal communities and wild dogs in Australia. Vet Parasitol. 2012;187:85-92.

23. Baszler TV, Adams S, Vander-Schalie J, Mathison BA, Kostovic M. Validation of a commercially available monoclonal antibody-based competitiveinhibition enzyme-linked immunosorbent assay for detection of serum antibodies to Neospora caninum in cattle. J Clin Microbiol. 2001;39:3851-7.

24. Capelli G, Natale A, Nardelli S. Frangipane di Regalbono a, Pietrobelli M. Validation of a commercially available cELISA test for canine neosporosis against an indirect fluorescent antibody test (IFAT). Prev Vet Med. 2006;73: 315-20.

25. Schares G, Pantchev N, Barutzki D, Heydorn AO, Bauer C, Conraths FJ. Oocysts of Neospora caninum, Hammondia heydorni, Toxoplasma gondii and Hammondia hammondi in faeces collected from dogs in Germany. Int J Parasitol. 2005;35:1525-37.

26. Pinheiro AF, Borsuk S, Berne ME, Pinto Lda S, Andreotti R, Roos T, et al. Use of ELISA based on NCSRS2 of Neospora caninum expressed in Pichia pastoris for diagnosing neosporosis in sheep and dogs. Rev Bras Parasitol Vet. 2015;24:148-54.

27. Šlapeta J, Modrý D, Kyselová I, Hořejš R, Lukeš J, Koudela B. Dog shedding oocysts of Neospora caninum: PCR diagnosis and molecular phylogenetic approach. Vet Parasitol. 2002;109:157-67.

28. McAllister MM, Funnell O, Donahoe SL, Šlapeta J. Unusual presentation of neosporosis in a neonatal puppy from a litter of bulldogs. Aust Vet J. 2016;94:411-4.

29. Prandini da Costa Reis R, Crisman R, Roser M, Malik R, Šlapeta J. Neonatal neosporosis in a 2-week-old Bernese mountain dog infected with multiple Neospora caninum strains based on MS10 microsatellite analysis. Vet Parasitol. 2016;221:134-8.

30. Dubey JP, Schares G, Ortega-Mora LM. Epidemiology and control of neosporosis and Neospora caninum. Clin Microbiol Rev. 2007;20:323-67.

31. Wapenaar W, Jenkins MC, O'Handley RM, Barkema HW. Neospora caninumlike oocysts observed in feces of free-ranging red foxes (Vulpes vulpes) and coyotes (Canis latrans). J Parasitol. 2006;92:1270-4.

32. Jenkins M, Baszler T, Bjorkman C, Schares G, Williams DJ. Diagnosis and seroepidemiology of Neospora caninum-associated bovine abortion. Int J Parasitol. 2002;32:631-6.

33. Dubey JP, Hattel AL, Lindsay DS, Topper MJ. Neonatal Neospora caninum infection in dogs: isolation of the causative agent and experimental transmission. J Am Vet Med Assoc. 1988:193:1259-63.

34. Dubey JP, Lindsay DS, Adams DS, Gay JM, Baszler TV, Blagburn BL, Thulliez P. Serologic responses of cattle and other animals infected with Neospora caninum. Am J Vet Res. 1996;57:329-36.
35. Ash A, Elliot A, Thompson ARC. The detection and characterisation of Neospora/Hammondia-like oocysts from naturally infected dogs within the same urban region of Australia. Vet Parasitol Reg Stud Rep. 2016;1-2:47-50.

36. Schares G, Heydorn AO, Cuppers A, Conraths FJ, Mehlhorn H. Cyclic transmission of Neospora caninum: serological findings in dogs shedding oocysts. Parasitol Res. 2001;87:873-7.

37. Schares G, Heydorn AO, Cuppers A, Conraths FJ, Mehlhorn H. Hammondia heydorni-like oocysts shed by a naturally infected dog and Neospora caninum NC-1 cannot be distinguished. Parasitol Res. 2001;87:808-16.

38. Dijkstra T, Eysker M, Schares G, Conraths FJ, Wouda W, Barkema HW. Dogs shed Neospora caninum oocysts after ingestion of naturally infected bovine placenta but not after ingestion of colostrum spiked with Neospora caninum tachyzoites. Int J Parasitol. 2001:31:747-52.

39. Lindsay DS, Dubey JP, Duncan RB. Confirmation that the dog is a definitive host for Neospora caninum. Vet Parasitol. 1999:82:327-33.

40. Dubey JP, Schares G. Diagnosis of bovine neosporosis. Vet Parasitol. 2006;140:1-34

41. Schares G, Heydorn AO, Cuppers A, Mehlhorn H, Geue L, Peters M, Conraths F. In contrast to dogs, red foxes (Vulpes vulpes) did not shed Neospora caninum upon feeding of intermediate host tissues. Parasitol Res. 2001;88:44-52.

42. Ogedengbe ME, Ogedengbe JD, Whale JC, Elliot K, Juarez-Estrada MA, Barta JR. Molecular phylogenetic analyses of tissue coccidia (Sarcocystidae; Apicomplexa) based on nuclear $18 \mathrm{~S}$ rDNA and mitochondrial CO sequences confirms the paraphyly of the genus Hammondia. Parasito Open. 2016;2

43. Hiasa J, Nishimura M, Itamoto K, Xuan X, Inokuma H, Nishikawa Y. Enzymelinked immunosorbent assays based on Neospora caninum dense granule protein 7 and profilin for estimating the stage of neosporosis. Clin Vaccine Immunol. 2012;19:411-7.

44. Chahan B, Gaturaga I, Huang X, Liao M, Fukumoto S, Hirata H, et al. Serodiagnosis of Neospora caninum infection in cattle by enzyme-linked immunosorbent assay with recombinant truncated NcSAG1. Vet Parasitol. 2003;118:177-85.

45. Kubota N, Sakata Y, Miyazaki N, Itamoto K, Bannai H, Nishikawa Y, et al. Serological survey of Neospora caninum infection among dogs in Japan through species-specific ELISA. J Vet Med Sci. 2008;70:869-72.

\section{Submit your next manuscript to BioMed Central and we will help you at every step:}

- We accept pre-submission inquiries

- Our selector tool helps you to find the most relevant journal

- We provide round the clock customer support

- Convenient online submission

- Thorough peer review

- Inclusion in PubMed and all major indexing services

- Maximum visibility for your research

Submit your manuscript at www.biomedcentral.com/submit 